\title{
Differential Activation and Desensitization of Sensory Neurons by Resiniferatoxin
}

\author{
Geza Acs, Tamas Biro, Peter Acs, Shayan Modarres, and Peter M. Blumberg \\ Molecular Mechanisms of Tumor Promotion Section, Laboratory of Cellular Carcinogenesis and Tumor Promotion, \\ National Cancer Institute, National Institutes of Health, Bethesda, Maryland 20892
}

\begin{abstract}
Recently, with use of rat dorsal root ganglion (DRG) neurons we have been able to dissociate the binding affinities of vanilloids from their potencies to induce ${ }^{45} \mathrm{Ca}$ uptake, which suggests the existence of distinct classes of the vanilloid receptor (Acs et al., 1996). In the present study, we have demonstrated that the ultrapotent capsaicin analog resiniferatoxin (RTX) desensitized rat DRG neurons to the subsequent induction of ${ }^{45} \mathrm{Ca}$ uptake by capsaicin and RTX with affinity and cooperativity similar to that found for $\left[{ }^{3} \mathrm{H}\right] \mathrm{RTX}$ binding, contrasting with a $\sim 10$-fold weaker potency and lack of cooperativity to induce ${ }^{45} \mathrm{Ca}$ uptake. Likewise, the competitive antagonist capsazepine inhibited RTXinduced desensitization with potency similar to that for inhibition of specific $\left[{ }^{3} \mathrm{H}\right] \mathrm{RTX}$ binding, whereas the potency of capsazepine was $\sim 10$-fold higher for inhibiting RTX-induced ${ }^{45} \mathrm{Ca}$ uptake. Finally, the noncompetitive antagonist ruthenium red inhibited both the RTX-induced desensitization and ${ }^{45} \mathrm{Ca}$
\end{abstract}

uptake but showed $\sim 60$-fold selectivity for inhibiting RTXinduced desensitization. The RTX-induced desensitization was not associated with loss of specific $\left[{ }^{3} \mathrm{H}\right] \mathrm{RTX}$ binding, suggesting lack of gross cell toxicity. In contrast to RTX, capsaicin caused desensitization with a potency corresponding to that for ${ }^{45} \mathrm{Ca}$ uptake and did so in a noncooperative manner. Unlike the RTX-induced desensitization, the desensitization by capsaicin was blocked by ruthenium red only at doses that blocked ${ }^{45} \mathrm{Ca}$ uptake and depended on external calcium. Our findings provide further support for the existence of vanilloid receptor subtypes on DRG neurons with distinct pharmacology and distinct patterns of desensitization.

Key words: dorsal root ganglion neurons; capsaicin; resiniferatoxin; desensitization; $\left[{ }^{3} \mathrm{H}\right] \mathrm{RTX}$ binding; ${ }^{45} \mathrm{Ca}$ uptake; capsazepine; ruthenium red; pain; rat
A subpopulation of primary afferent neurons, located in the dorsal root and trigeminal ganglia, can be defined by their selective susceptibility to the effects of capsaicin (Buck and Burks, 1986; Holzer, 1991), the major pungent ingredient of hot peppers of the plant genus Capsicum.

Several years ago we found that resiniferatoxin (RTX), a naturally occurring irritant tricyclic diterpene (Hergenhahn et al., 1975 ) that combines structural features of the phorbol ester tumor promoters and of capsaicin, functions as an ultrapotent capsaicin analog (Szallasi and Blumberg, 1989). Qualitatively, RTX induces a pattern of responses generally similar to those observed for capsaicin (Szallasi and Blumberg, 1989). RTX and capsaicin differ, however, in their relative potencies for different responses (Blumberg et al., 1993).

As observed for capsaicin, after initial excitation, RTX treatment also leads to desensitization to subsequent RTX application; in addition, desensitization by either compound leads to crossdesensitization to the other (Blumberg et al., 1993). It was postulated decades ago that pungency of capsaicin analogs is proportional to the desensitization that follows (Jancso, 1968); however, this does not seem to be the case for RTX. For example, similar concentrations of RTX and capsaicin cause contraction of isolated rat urinary bladder, but RTX shows a 1000 -fold higher potency to induce desensitization (Maggi et al., 1990). Moreover, RTX, but

Received Feb. 7, 1997; revised April 29, 1997; accepted May 6, 1997.

G. Acs and T. Biro contributed equally to this work.

Correspondence should be addressed to Dr. Peter M. Blumberg, MMTP/LCCTP/ NCI, Building 37, Room 3A01, 37 Convent Drive MSC 4255, Bethesda, MD 20892-4255.

Copyright (C) 1997 Society for Neuroscience $0270-6474 / 97 / 175622-07 \$ 05.00 / 0$ not capsaicin, can desensitize the pulmonary $\mathrm{J} 1$ receptors of the rat without previous excitation (Szolcsanyi et al., 1990).

$\left[{ }^{3} \mathrm{H}\right] \mathrm{RTX}$ shows specific, saturable binding to membranes of sensory afferent neurons, displaying appropriate tissue, species, and pharmacological specificity to represent the vanilloid receptor (Blumberg et al., 1993; Acs et al., 1994a,b). Specific $\left[{ }^{3} \mathrm{H}\right] \mathrm{RTX}$ binding by the above membrane preparations displays sigmoidal saturation kinetics, indicating apparent positive cooperativity (Acs et al., 1994a,b).

The basis for the differences in the pattern of responses to capsaicin and RTX and the divergence between the stimulatory and desensitizing potencies of vanilloids has remained unresolved. Consistent with the existence of receptor subclasses (Holzer, 1991; Blumberg et al., 1993), different vanilloid analogs show different potencies for receptor binding and for induction of ${ }^{45} \mathrm{Ca}$ uptake in dorsal root ganglion (DRG) neurons when assayed under similar conditions (Acs et al., 1996). Likewise, both RTX and capsaicin bind to DRG neurons in a positive cooperative fashion but induce ${ }^{45} \mathrm{Ca}$ uptake in a noncooperative manner (Acs et al., 1996).

In the present study, we have examined whether we can identify any responses in the DRG neurons linked to the high-affinity RTX receptor as defined by $\left[{ }^{3} \mathrm{H}\right] \mathrm{RTX}$ binding. We conclude that this site mediates desensitization of ${ }^{45} \mathrm{Ca}$ uptake to subsequent vanilloid challenge. We further demonstrate that stimulation of the ${ }^{45} \mathrm{Ca}$ uptake site by capsaicin can alternatively desensitize the cells to subsequent vanilloid challenge. These two pathways of desensitization show different sensitivities to ruthenium red and different dependence on external $\mathrm{Ca}^{2+}$. On the one hand, our findings strengthen the evidence for multiple vanilloid receptors; 
on the other hand, they help rationalize the extensive evidence for the complexity of "desensitization" in response to vanilloids (Holzer, 1991).

\section{MATERIALS AND METHODS}

Female Sprague Dawley rats (6-8 weeks old, $150-160$ gm body weight) were purchased from NCI-FCRDC (Frederick, MD). Animals were allowed to access food and water ad libitum throughout the course of the experiments. Animal protocols were approved by the Animal Care and Use Subcommittee, Division of Basic Sciences, National Cancer Institute. $\left[{ }^{3} \mathrm{H}\right] \mathrm{RTX}(37 \mathrm{Ci} / \mathrm{mmol})$ was synthesized by the Chemical Synthesis and Analysis Laboratory, NCI-FCRDC. ${ }^{45} \mathrm{Ca}\left(\mathrm{CaCl}_{2}, 23.55 \mathrm{mCi} / \mathrm{mg}\right)$ was purchased from DuPont NEN (Boston, MA). Nonradioactive RTX and capsazepine were from LC Laboratories (Woburn, MA). Capsaicin was from Sigma (St. Louis, MO). Ruthenium red was purchased from Research Biochemicals International (Natick, MA).

Cell cultures. Rat DRG neuron cultures were prepared as described (Acs et al., 1995, 1996). Animals were decapitated under $\mathrm{CO}_{2}$ anesthesia. The spinal columns were removed aseptically, and DRGs from all levels were dissected out and collected in ice-cold DMEM (Life Technologies, Gaithersburg, MD) containing $0.5 \%$ heat-inactivated fetal bovine serum (Life Technologies), $1 \mathrm{~mm}$ sodium pyruvate, and $25 \mathrm{~mm}$ HEPES. Ganglia were digested with $0.125 \%$ collagenase (Sigma) in DMEM for 90 min at $37^{\circ} \mathrm{C}$ and then for an additional $90 \mathrm{~min}$ in fresh collagenase solution. Ganglia were washed twice with DMEM containing $25 \mathrm{mM}$ HEPES and $1 \mathrm{~mm}$ sodium pyruvate and were triturated through a flame-polished Pasteur pipette to form a single cell suspension. The cells were pelleted through a cushion of DMEM containing $15 \%$ fatty acid-free bovine serum albumin (BSA) (Sigma) to remove myelin debris. Cells were then washed three times with serum-free DMEM and resuspended in the same medium, and the number of viable cells was determined by the Trypan-blue dye exclusion test. Cells were then plated into MultiScreen-DV 96-well filtration plates (Millipore, Marlborough, MA) at a density of $\sim 5 \times 10^{3}$ cells/well in $100 \mu$ l of serum-free medium.

For desensitization experiments, cells were incubated at $37^{\circ} \mathrm{C}$ in the presence of RTX or capsaicin for the indicated times before measurement of induction of ${ }^{45} \mathrm{Ca}$ uptake. Alternatively, the cells in suspension were treated with RTX and competing ligands (capsazepine or ruthenium red). After incubation at $37^{\circ} \mathrm{C}$ for $6 \mathrm{hr}$, cells were washed three times with serum-free DMEM containing $0.25 \mathrm{mg} / \mathrm{ml} \mathrm{BSA}$ and then challenged with either capsaicin or RTX to induce ${ }^{45} \mathrm{Ca}$ uptake. The efficacy of the washing procedure was quantitated in the following way. Cells were incubated in the presence of $250 \mathrm{pM}\left[{ }^{3} \mathrm{H}\right] \mathrm{RTX}$ (the concentration of RTX used in most experiments for inducing desensitization) for $6 \mathrm{hr}$. The radioactivity in the cell suspension was determined before washing and after each washing step by scintillation counting. According to these experiments, $\sim 95 \%$ of the added radioactive RTX was removed by this washing procedure from the suspension (see insert in Fig. 5). The number of viable cells was then determined. Cells were then plated into Multiscreen-DV 96-well filtration plates at a density of $\sim 5 \times 10^{3}$ cells/ well in $100 \mu \mathrm{l}$ serum-free medium and used for ${ }^{45} \mathrm{Ca}$ uptake and $\left[{ }^{3} \mathrm{H}\right]$ RTX binding assays.

Measurement of ${ }^{45} \mathrm{Ca}$ uptake by DRG neurons. Freshly dissociated cells in MultiScreen-DV 96-well filtration plates were incubated in a total volume of $0.25 \mathrm{ml}$ of serum-free DMEM (containing $1.8 \mathrm{mM} \mathrm{CaCl}_{2}$ ) in the presence of $0.25 \mathrm{mg} / \mathrm{ml} \mathrm{BSA}$ (included to stabilize the compounds in the aqueous solution), $1 \mu \mathrm{Ci} / \mathrm{ml}{ }^{45} \mathrm{Ca}$, and increasing concentrations of the different compounds for $20 \mathrm{~min}$ at $37^{\circ} \mathrm{C}$ (Acs et al., 1995, 1996). Cells were then washed five times with ice-cold DMEM by filtration using a MultiScreen Vacuum Manifold (Millipore). Filters were dried under a heat lamp and punched out into scintillation vials using MultiScreen disposable punch tips, and the radioactivity was determined by scintillation counting. For each data point in each experiment, eight wells were assayed.

Analysis of ${ }^{45}$ Ca uptake data. Analysis of the ${ }^{45} \mathrm{Ca}$ uptake experiments was performed as described previously (Acs et al., 1996) by computer fit to the Hill equation (Endrenyi et al., 1975). In the case of experiments performed on RTX or capsaicin-pretreated cells, desensitization was defined as the difference (in dpm/well) between the increase in ${ }^{45} \mathrm{Ca}$ uptake in these and in control cells after challenge by capsaicin or RTX. The decrease in the ${ }^{45} \mathrm{Ca}$ uptake induced by vanilloids was plotted against the pretreatment concentration of RTX, and the data were fitted to the Hill equation. Data from competition experiments in which the effect of the desensitizing compound was antagonized by either a com- petitive (capsazepine) or a noncompetitive (ruthenium red) antagonist were fitted to the modified Hill equation (Davis et al., 1977). Data were fitted to the equations using the computer program MicroCal Origin 3.5 (MicroCal Software, Northampton, MA). For the statistical analysis of the curve fitting to the experimental data, the $\chi^{2}$ test of goodness of fit was used.

Measurement of $\left[{ }^{3} \mathrm{H}\right] \mathrm{RTX}$ binding by DRG neurons. For $\left[{ }^{3} \mathrm{H}\right] \mathrm{RTX}$ binding assays, cells were plated into Multiscreen-DV 96-well filtration plates (Acs et al., 1996). Immediately after plating, $150 \mu \mathrm{l}$ of DMEM containing $0.25 \mathrm{mg} / \mathrm{ml} \mathrm{BSA},\left[{ }^{3} \mathrm{H}\right] \mathrm{RTX}$, and nonradioactive ligands was added to each well containing the $100 \mu \mathrm{l}$ cell suspension, and the plates were incubated in triplicate for $60 \mathrm{~min}$ at $37^{\circ} \mathrm{C}$. Plates were then chilled on ice, and $1 \mathrm{mg}$ of $\alpha_{1}$-acid glycoprotein (AGP, Sigma) in $50 \mu \mathrm{l}$ of ice-cold serum-free DMEM was added to each well to reduce nonspecific binding (Szallasi et al., 1992). Cells were then washed four times with DMEM $(200 \mu \mathrm{l} /$ well $)$ containing $0.5 \mathrm{mg} / \mathrm{ml}$ AGP by filtration using a MultiScreen Vacuum Manifold (Millipore). Filters were dried under a heat lamp and punched out into scintillation vials using MultiScreen disposable punch tips, and the bound radioactivity was determined by scintillation counting. Binding was expressed as femtomoles $/ 10^{3}$ cells; nonspecific binding was determined in the presence of $1 \mu \mathrm{M}$ nonradioactive RTX.

\section{RESULTS}

The potencies of RTX and capsaicin to stimulate the uptake of calcium into rat DRG neurons were determined in the presence of $1 \mu \mathrm{Ci} / \mathrm{ml}{ }^{45} \mathrm{Ca}$. As expected, both ligands induced a dosedependent increase in ${ }^{45} \mathrm{Ca}$ uptake by the cells with $\mathrm{ED}_{50}$ values of $1.24 \pm 0.02 \mathrm{nM}$ for RTX and $316 \pm 47 \mathrm{~nm}$ for capsaicin (mean \pm SEM for four experiments each). Hill coefficients for the dose-response curves were close to unity $(1.08 \pm 0.07$ and $1.02 \pm$ 0.06 in the case of RTX and capsaicin, respectively; mean \pm SEM for four experiments) ( $p>0.05$; Student's $t$ test), suggesting a noncooperative mechanism of action. These values agreed well with those determined previously (Acs et al., 1996).

We had reported previously (Acs et al., 1996) that RTX displayed 24-fold greater potency for specific binding to DRG neurons than for induction of ${ }^{45} \mathrm{Ca}$ uptake. We were interested in how the low concentrations of RTX, at which binding was measured, affected the induction of ${ }^{45} \mathrm{Ca}$ uptake on subsequent capsaicin treatment. We first determined the effect of RTX pretreatment for different time intervals on ${ }^{45} \mathrm{Ca}$ uptake after challenge with capsaicin. Preincubation of the neurons with $100 \mathrm{pm}$ (a concentration close to the $K_{\mathrm{d}}$ value of RTX for receptor binding) and 250 pM RTX (a concentration that almost saturates RTX binding sites) (Acs et al., 1996) for $10 \mathrm{~min}$ had no effect on the level of ${ }^{45} \mathrm{Ca}$ uptake when the cells were stimulated with $3 \mu \mathrm{M}$ capsaicin (a dose that by itself induces a maximal stimulation of ${ }^{45} \mathrm{Ca}$ uptake by the cells) (Acs et al., 1995, 1996) (Fig. 1A). In contrast, a significant decrease of ${ }^{45} \mathrm{Ca}$ uptake $(20.8 \pm 1.3$ and $33.6 \pm 2.1 \%$ decrease compared with control uptake, respectively; mean \pm SEM for three experiments each) $(p<0.05$; Student's $t$ test) was observed in both cases after $30 \mathrm{~min}$ of preincubation with RTX. A maximal effect of RTX pretreatment $(55.7 \pm 3.3$ and $91.2 \pm 1.8 \%$ decrease in ${ }^{45} \mathrm{Ca}$ uptake in the case of 100 and 250 pM RTX pretreatment, respectively, compared with control cells; mean \pm SEM for three experiments each) was reached in both cases by $5 \mathrm{hr}$ of preincubation. On the basis of the above results, a $6 \mathrm{hr}$ preincubation time was used in the subsequent experiments to induce maximal desensitization to RTX.

To determine the concentration dependence of RTX-induced desensitization, neurons were incubated with different concentrations of RTX for $6 \mathrm{hr}$. This procedure resulted in a dosedependent reduction in the level of ${ }^{45} \mathrm{Ca}$ uptake after challenge with $3 \mu \mathrm{M}$ capsaicin (Fig. 1B). Fitting the desensitization curves (see Materials and Methods) to the Hill equation yielded an 

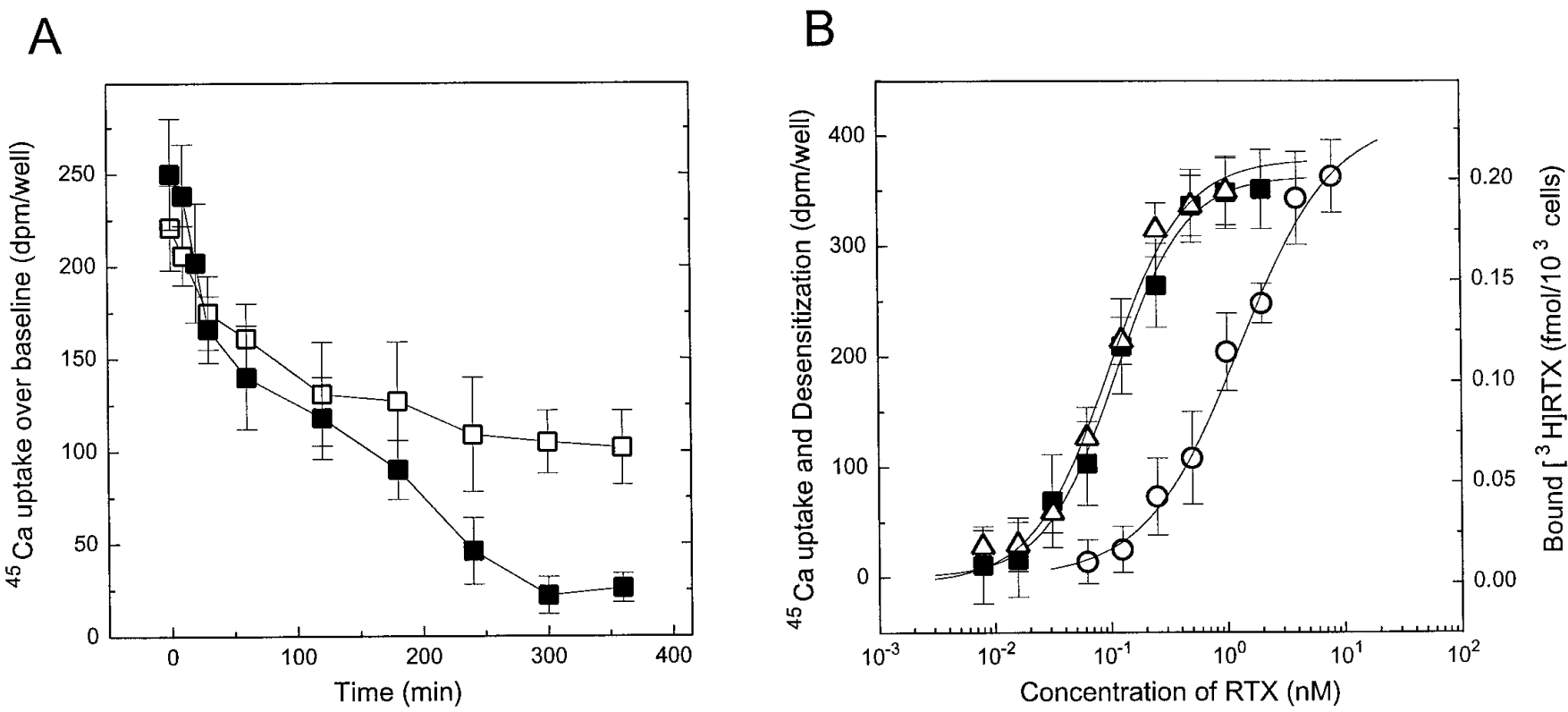

Figure 1. Inhibition of ${ }^{45} \mathrm{Ca}$ uptake in rat DRG neurons after RTX pretreatment. $A$, Time course of the effect of RTX pretreatment on ${ }^{45} \mathrm{Ca}$ uptake. Cells were pretreated with $100 \mathrm{pm}(\square)$ and $250 \mathrm{pm}(\mathbf{\square})$ resiniferatoxin and then challenged with $3 \mu \mathrm{M}$ capsaicin. Two additional experiments yielded similar results. $B$, Comparison of dose-response curves for induction of ${ }^{45} \mathrm{Ca}$ uptake, $\left[{ }^{3} \mathrm{H}\right] \mathrm{RTX}$ binding, and desensitization by RTX in rat DRG neurons. Data are expressed as uptake values above baseline for RTX-induced ${ }^{45} \mathrm{Ca}$ uptake $(\bigcirc)$ and as specifically bound $\left[{ }^{3} \mathrm{H}\right] \mathrm{RTX}(\triangle)$ when binding was determined. Desensitization was defined as the difference (in dpm/well) in ${ }^{45} \mathrm{Ca}$ uptake between pretreated and control cells challenged with capsaicin. In the case of desensitization ( $\mathbf{\square})$, cells were pretreated with different concentrations of RTX for $6 \mathrm{hr}$ and then challenged with $3 \mu \mathrm{M}$ capsaicin. Points represent mean values from sets of eight determinations in a single experiment; error bars indicate SEM. The theoretical curves were calculated by fitting the measured values to the Hill equation. In the case of ${ }^{45} \mathrm{Ca}$ uptake and desensitization, three additional experiments in each case yielded similar results. The dose-response curve for $\left[{ }^{3} \mathrm{H}\right] \mathrm{RTX}$ binding is a single experiment, yielding binding parameters similar to those we found previously (Acs et al., 1996).

apparent $K_{\mathrm{d}}$ value for desensitization of $81 \pm 5$ pM and a Hill coefficient of $1.51 \pm 0.11$ (mean \pm SEM for four experiments), suggesting positive cooperativity of RTX action. The potency of RTX for desensitization thus was $\sim 10$-fold higher than that for induction of ${ }^{45} \mathrm{Ca}$ uptake and was similar to its affinity for receptor binding ( $47 \pm 4 \mathrm{pM}$ ) (Acs et al., 1996). Moreover, RTX desensitized the cells in a positive cooperative fashion-with a Hill coefficient similar to that determined in receptor binding assays (1.78 \pm 0.12 ) (Acs et al., 1996)—as opposed to its noncooperative action in ${ }^{45} \mathrm{Ca}$ uptake induction assays.

In the above experiments, we desensitized with RTX and challenged with capsaicin. In other experiments we challenged the 250 pM RTX-pretreated cells with as high a dose of RTX as $200 \mathrm{~nm}$. The $K_{\mathrm{d}}$ and Hill coefficient values for desensitization were similar to those after capsaicin challenge $\left(K_{\mathrm{d}}\right.$ and Hill coefficient values were $91 \pm 6 \mathrm{nM}$ and $1.62 \pm 0.24$, respectively; mean \pm SEM for five experiments).

The desensitization of ${ }^{45} \mathrm{Ca}$ uptake was independent of the challenging dose of capsaicin or RTX. Pretreatment of the neurons with $250 \mathrm{pM}$ RTX (a concentration that by itself induced only $11.7 \pm 1.5 \%$ of maximal ${ }^{45} \mathrm{Ca}$ uptake response; mean \pm SEM for four experiments) almost completely (92.1 $\pm 2.8 \%$; mean \pm SEM for four experiments, for challenge by $3 \mu \mathrm{M}$ capsaicin) abolished the induction of ${ }^{45} \mathrm{Ca}$ uptake by capsaicin up to a concentration of $6.4 \mu \mathrm{M}$ (data not shown). Likewise, pretreatment of the cells with $250 \mathrm{pm}$ RTX for $6 \mathrm{hr}$ also abolished the ${ }^{45} \mathrm{Ca}$ uptake induced by $200 \mathrm{~nm}$ RTX by $90.3 \pm 3.1 \%$ (mean \pm SEM for five experiments) (data not shown). These results suggest that the decrease in ${ }^{45} \mathrm{Ca}$ uptake stimulated by a subsequent challenge could not be attributed to competition at the site coupled to the ${ }^{45} \mathrm{Ca}$ uptake. Further support for this conclusion comes from experiments in which the cells were washed three times after RTX preincubation immediately before the capsaicin challenge (this procedure removed $>95 \%$ of the 250 pM RTX used for pretreatment) (for details, see Materials and Methods). The washing had no effect on the level of desensitization caused by the pretreatment (data not shown). We conclude that the RTX-induced desensitization does not require the continuous presence of RTX on the receptors.

As shown in Figure $1 B,\left[{ }^{3} \mathrm{H}\right] \mathrm{RTX}$ displayed specific binding to rat DRG neurons. At $4 \mathrm{nM}\left[{ }^{3} \mathrm{H}\right] \mathrm{RTX}$, a concentration sufficient to saturate the receptors, the receptor density in control cells was $0.140 \pm 0.002 \mathrm{fmol} / 10^{3}$ cells. This value agreed well with those determined previously (Acs et al., 1996). Under similar conditions, in cells pretreated with $250 \mathrm{pm}$ RTX for $6 \mathrm{hr}$ and in cells to which 250 pM RTX was added immediately before the binding assay, we determined similar values of specifically bound $\left[{ }^{3} \mathrm{H}\right]$ RTX of $0.129 \pm 0.002$ and $0.125 \pm 0.001 \mathrm{fmol} / 10^{3}$ cells, respectively. When we determined the density of RTX binding sites after washing the cells three times after RTX pretreatment, we observed values of specifically bound $\left[{ }^{3} \mathrm{H}\right] \mathrm{RTX}$ of $0.139 \pm$ 0.002 and $0.141 \pm 0.008 \mathrm{fmol} / 10^{3}$ cells, respectively. In neither case did the pretreated cells significantly differ from the corresponding control ( $p>0.05$; Student's $t$ test). We conclude that the observed decrease in ${ }^{45} \mathrm{Ca}$ uptake after RTX pretreatment could not be attributed to the downregulation of the vanilloid receptor as detected by the $\left[{ }^{3} \mathrm{H}\right] \mathrm{RTX}$ binding assay. This observation further demonstrates the lack of toxicity of the $6 \mathrm{hr}$ incubation with $250 \mathrm{pm}$ RTX. Likewise, the number of viable neurons was not changed after RTX treatment, and the baseline 


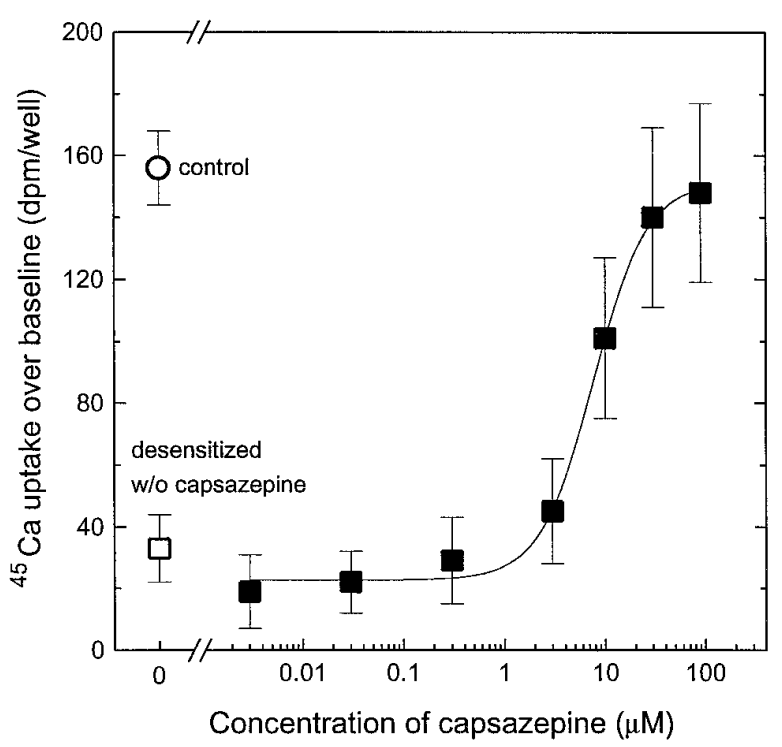

Figure 2. Inhibition of RTX-induced desensitization of rat DRG neurons by capsazepine. Cells were incubated in the presence of 250 pM RTX and different concentrations of capsazepine for $6 \mathrm{hr}$. Cells were then washed three times with serum-free DMEM containing $0.25 \mathrm{mg} / \mathrm{ml}$ BSA to remove the above compounds and were then challenged with $200 \mathrm{nM}$

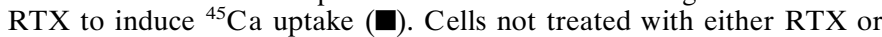
capsazepine $(\bigcirc$, control) or treated with only 250 pM RTX for $6 \mathrm{hr}(\square)$ are shown as control values. Points represent mean values from sets of eight determinations in a single experiment; error bars indicate SEM. The theoretical curve was calculated by fitting the measured values to the Hill equation. Two additional experiments yielded similar results.

uptake of ${ }^{45} \mathrm{Ca}$ was the same in pretreated and control cells (data not shown).

As observed previously (Acs et al., 1996), the competitive antagonist capsazepine (Bevan et al., 1992; Szallasi et al., 1993) inhibited stimulation of ${ }^{45} \mathrm{Ca}$ uptake by $500 \mathrm{~nm}$ capsaicin in a noncooperative fashion. $K_{\mathrm{i}}$ and Hill coefficient values were $291 \pm$ $31 \mathrm{nM}$ and $0.98 \pm 0.03$, respectively (mean \pm SEM for three experiments). Capsazepine likewise inhibited ${ }^{45} \mathrm{Ca}$ uptake into rat DRG neurons induced by $200 \mathrm{~nm}$ RTX with similar $K_{\mathrm{i}}$ and Hill coefficient values of $351 \pm 39 \mathrm{nM}$ and $1.07 \pm 0.08$ (mean $\pm \mathrm{SEM}$ for four experiments) (data not shown).

To determine whether capsazepine also acted as an antagonist of RTX-induced desensitization, we pretreated the cells with 250 pM RTX and different concentrations of capsazepine for $6 \mathrm{hr}$, washed them three times, and then challenged them with $200 \mathrm{~nm}$ RTX. This high challenging concentration of RTX ( 200-fold its $K_{\mathrm{d}}$ for induction of ${ }^{45} \mathrm{Ca}$ uptake) was used to assure complete displacement of capsazepine from both the ${ }^{45} \mathrm{Ca}$ uptake site and the specific $\left[{ }^{3} \mathrm{H}\right] \mathrm{RTX}$ binding site. Using the washing protocol (see Materials and Methods), we were able to show that capsazepine inhibited the RTX-induced desensitization in a dosedependent fashion (Fig. 2), yielding a $K_{\mathrm{i}}$ of $3.66 \pm 0.71 \mu \mathrm{M}$ and a Hill coefficient value of $1.83 \pm 0.11$ (mean \pm SEM for four experiments), suggesting apparent positive cooperativity. These data are in good accord with the $K_{\mathrm{i}}$ and Hill coefficient values of capsazepine for inhibiting specific $\left[{ }^{3} \mathrm{H}\right] \mathrm{RTX}$ binding to DRG neurons (3.16 $\pm 0.21 \mu \mathrm{M}$ and $1.72 \pm 0.11$, respectively) (Acs et al., 1996) and contrast with the respective values of capsazepine for blocking RTX-induced ${ }^{45} \mathrm{Ca}$ uptake (see above). By itself, capsazepine did not cause desensitization.

Similar experiments were performed with the noncompetitive

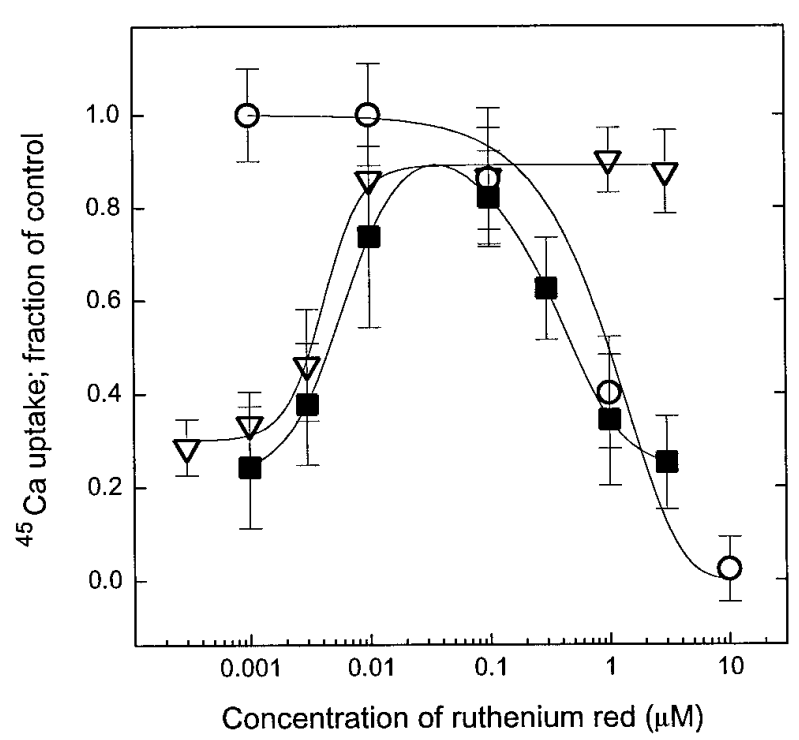

Figure 3. Effect of ruthenium red on RTX-induced ${ }^{45} \mathrm{Ca}$ uptake and on RTX-induced desensitization in rat DRG neurons. Cells were incubated in the presence of $250 \mathrm{pM}$ RTX and different concentrations of ruthenium red for $6 \mathrm{hr}$ and then challenged with $200 \mathrm{nM}$ RTX ( $\square)$. To evaluate the effect of ruthenium red just on desensitization, after the above incubation cells were washed three times with serum-free DMEM containing 0.25 $\mathrm{mg} / \mathrm{ml} \mathrm{BSA}$ to remove the pretreatment compounds before the cells were challenged to induce ${ }^{45} \mathrm{Ca}$ uptake $(\nabla)$. To measure the effect of ruthenium red just on ${ }^{45} \mathrm{Ca}$ uptake, varying concentrations of ruthenium red and 200 nM RTX were applied together, and ${ }^{45} \mathrm{Ca}$ uptake was determined (O). Points represent mean values from sets of eight determinations in a single experiment; error bars indicate SEM. The theoretical curve for blocking the RTX-induced ${ }^{45} \mathrm{Ca}$ uptake was calculated by fitting the measured values to the modified Hill equation, whereas data for blocking the RTX-induced desensitization was fitted to the Hill equation. Two additional experiments yielded similar results.

vanilloid receptor antagonist ruthenium red (Amann and Maggi, 1991). When applied together with RTX, ruthenium red blocked the ${ }^{45} \mathrm{Ca}$ uptake into the cells induced by $200 \mathrm{~nm}$ RTX in a dose-dependent fashion, with an $\mathrm{ED}_{50}$ of $790 \pm 40 \mathrm{~nm}$ (mean \pm SEM for three determinations) (Fig. 3); this value agreed well with those reported previously (Maggi et al., 1988). Furthermore, when administered together with $250 \mathrm{pm}$ RTX during the $6 \mathrm{hr}$ pretreatment, ruthenium red had a biphasic effect on ${ }^{45} \mathrm{Ca}$ uptake induced by a subsequent challenge with 200 nM RTX. At lower concentrations ruthenium red inhibited RTX-induced desensitization, which was reflected by the increased ${ }^{45} \mathrm{Ca}$ uptake into the cells. At higher concentrations, however, ruthenium red inhibited the ${ }^{45} \mathrm{Ca}$ uptake induced by the challenging dose of RTX. When the cells were washed three times after pretreatment with RTX and ruthenium red, the second phase of the above curve was eliminated (no ruthenium red was present in the assay to block ${ }^{45} \mathrm{Ca}$ uptake) (Fig. 3). In these latter experiments ruthenium red inhibited $250 \mathrm{pm}$ RTX-induced desensitization with an $\mathrm{ED}_{50}$ of $14 \pm 2 \mathrm{nM}$ (mean \pm SEM for three determinations), a value markedly different ( $\sim 60$-fold difference in potencies) from that determined for the inhibition of induction of the ${ }^{45} \mathrm{Ca}$ uptake. The ability of ruthenium red to inhibit selectively the RTXinduced desensitization is of great importance. It argues strongly that the desensitization observed in response to RTX does not reflect simply a long-term consequence of limited $\mathrm{Ca}^{2+}$ influx occurring at a concentration of ligand below the $\mathrm{ED}_{50}$ for stimulation of ${ }^{45} \mathrm{Ca}$ uptake. 

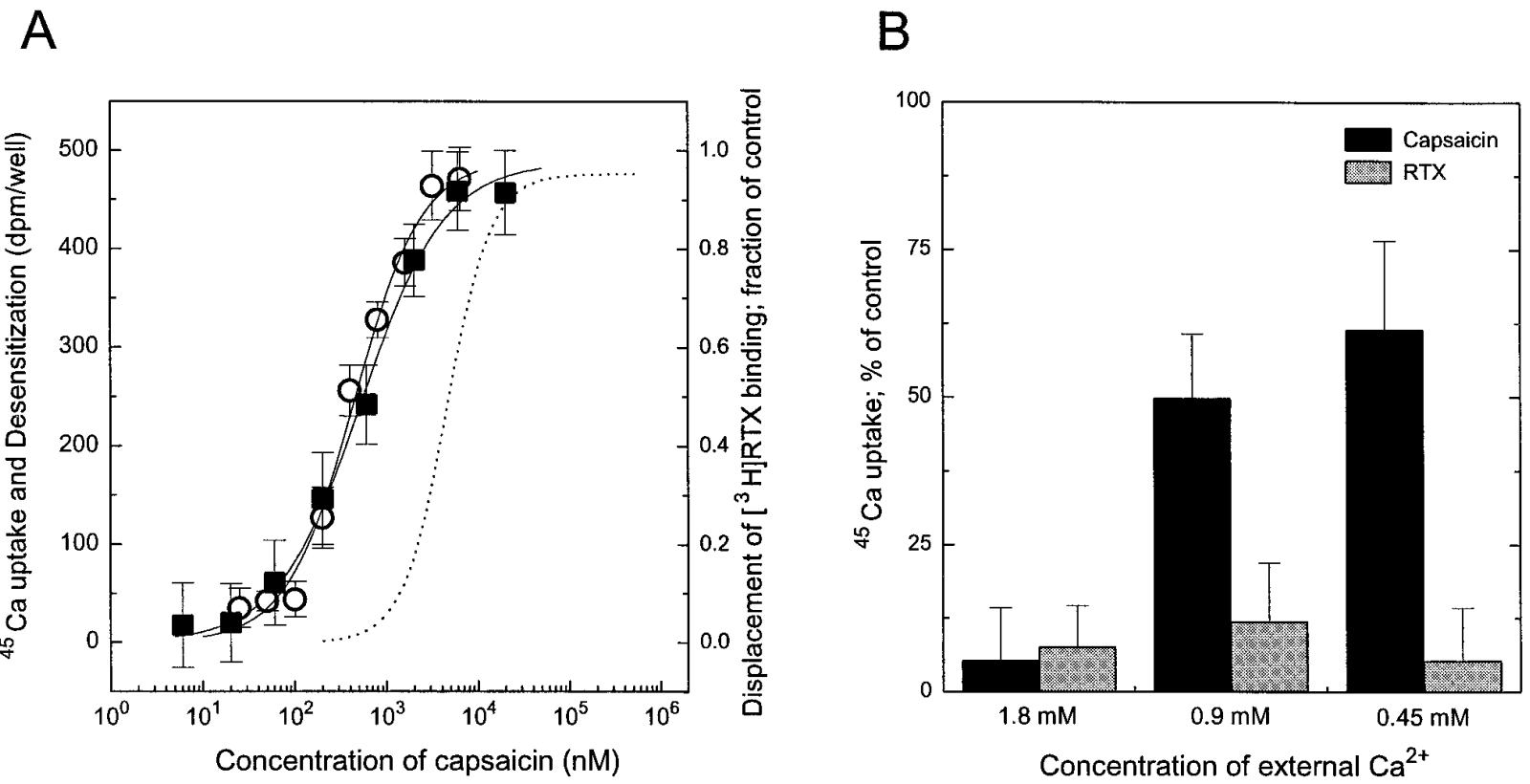

Figure 4. A, Comparison of dose-response curves for induction of ${ }^{45} \mathrm{Ca}$ uptake, desensitization, and displacement of [ $\left.{ }^{3} \mathrm{H}\right] \mathrm{RTX}$ binding by capsaicin in rat DRG neurons. Data are expressed as dpm/well values over baseline for capsaicin-induced ${ }^{45} \mathrm{Ca}$ uptake $(O)$. In the case of desensitization $(\mathbf{\square})$, cells were pretreated with different concentrations of capsaicin for $6 \mathrm{hr}$ and then challenged with $3 \mu \mathrm{M}$ capsaicin. Desensitization was defined as the difference (in dpm/well) in ${ }^{45} \mathrm{Ca}$ uptake between pretreated and control cells challenged with capsaicin. For comparison, the capsaicin dose-response curve for displacement of [ $\left.{ }^{3} \mathrm{H}\right] \mathrm{RTX}$ binding (dotted line), determined previously by us (Acs et al., 1996), was plotted. Points represent mean values from sets of eight determinations in a single experiment; error bars indicate SEM. The theoretical curves were calculated by fitting the measured values to the Hill equation. Two additional experiments in each case yielded similar results. $B$, Extracellular $\mathrm{Ca}^{2+}$ dependence of the capsaicin-induced desensitization of rat DRG neurons. Cells were incubated with either $250 \mathrm{pm}$ RTX or $1 \mu \mathrm{M}$ capsaicin for $4 \mathrm{hr}$ in medium that contained $1.8 \mathrm{~mm}, 0.9 \mathrm{mM}$, or $0.45 \mathrm{~mm}$ $\mathrm{Ca}^{2+}$. After incubation, cells were washed with serum-free DMEM containing $1.8 \mathrm{mM} \mathrm{Ca}^{2+}$ and challenged with $3 \mu \mathrm{M}$ capsaicin to induce ${ }^{45} \mathrm{Ca}$ uptake. Data were expressed as percentage values of control ${ }^{45} \mathrm{Ca}$ uptake determined on untreated cells in the same medium. The external $\mathrm{Ca}^{2+}$ dependence of desensitization is indicated by the return of the ${ }^{45} \mathrm{Ca}$ uptake response. Points represent mean values from sets of eight determinations in a single experiment; error bars indicate SEM. Two additional experiments yielded similar results.

The motivation for the above studies was to determine whether we could identify any responses that were coupled to the vanilloid receptor subtype detected by $\left[{ }^{3} \mathrm{H}\right] \mathrm{RTX}$ binding. We conclude that this receptor subclass is associated with desensitization of subsequent ${ }^{45} \mathrm{Ca}$ uptake in response to vanilloid challenge. These studies do not address the converse issue, whether the vanilloid receptor subtype detected by ${ }^{45} \mathrm{Ca}$ uptake can also induce desensitization. We therefore treated the cultured DRG neurons with capsaicin, which is selective for inducing ${ }^{45} \mathrm{Ca}$ uptake and has weaker affinity for the receptor defined by specific $\left[{ }^{3} \mathrm{H}\right] \mathrm{RTX}$ binding, and we determined the effect of capsaicin pretreatment on the subsequent ${ }^{45} \mathrm{Ca}$ uptake induced by vanilloid challenge. The stimulation of ${ }^{45} \mathrm{Ca}$ uptake was inhibited by capsaicin pretreatment with an $\mathrm{ED}_{50}$ of $445 \pm 46 \mathrm{~nm}$ (Fig. $4 A$ ). This value compares closely with the $\mathrm{ED}_{50}$ for induction of ${ }^{45} \mathrm{Ca}$ uptake by capsaicin, $316 \pm 47 \mathrm{nM}$, and is thus markedly lower than that for inhibition of $\left[{ }^{3} \mathrm{H}\right] \mathrm{RTX}$ binding by capsaicin $\left(K_{\mathrm{i}}\right.$ of $\left.4.9 \mu \mathrm{M}\right)$ (Acs et al., 1996). Furthermore, capsaicin induced desensitization in a noncooperative manner (with a Hill coefficient of $0.89 \pm 0.15$; mean \pm SEM for three experiments), similar to its action on inducing ${ }^{45} \mathrm{Ca}$ uptake (see above) and in contrast to the displacement of $\left[{ }^{3} \mathrm{H}\right] \mathrm{RTX}$ binding (Hill coefficient of 1.81) (Acs et al., 1996).

We next compared the dependence of the desensitization induced by either RTX or capsaicin on the concentration of $\mathrm{Ca}^{2+}$ in the medium. Because the DRG neurons show toxicity to prolonged incubation in the absence of extracellular $\mathrm{Ca}^{2+}$, we determined that desensitization in media containing decreased $\mathrm{Ca}^{2+}$ concentrations after $4 \mathrm{hr}$ preincubation (Fig. $4 B$ ). Desen- sitization by $250 \mathrm{pm}$ RTX was not affected by the change in the concentration of $\mathrm{Ca}^{2+}$ in the medium, whereas desensitization by $1 \mu \mathrm{M}$ capsaicin was reduced in media containing a decreased concentration of $\mathrm{Ca}^{2+}$.

Finally, consistent with the desensitization in response to capsaicin reflecting the induction of ${ }^{45} \mathrm{Ca}$ uptake, we compared the ability of ruthenium red to block the capsaicin and RTX-induced desensitization. We examined concentrations of ruthenium red that were three- to fourfold the $\mathrm{ED}_{50}$ for blocking RTX-induced desensitization and ${ }^{45} \mathrm{Ca}$ uptake (60 $\mathrm{nm}$ and $2 \mu \mathrm{M}$, respectively). Only the latter concentration inhibited the desensitization induced by $1 \mu \mathrm{M}$ capsaicin; in contrast, the desensitization induced by 250 pм RTX was already inhibited by 60 nм ruthenium red, as expected (Fig. 5). We conclude that capsaicin induces desensitization through a mechanism distinct from that of RTX. The capsaicin-induced desensitization is linked to the enhanced $\mathrm{Ca}^{2+}$ influx; the RTX-induced desensitization is mediated by the receptor detected by specific $\left[{ }^{3} \mathrm{H}\right] \mathrm{RTX}$ binding.

\section{DISCUSSION}

Our findings cogently argue for the existence of two pharmacologically defined classes of vanilloid receptors, for which we suggest the designation $\mathrm{R}(\mathrm{TX})$-type and C(apsaicin)-type. The distinct pharmacology of these two receptor subclasses had already been demonstrated in our comparison of $\left[{ }^{3} \mathrm{H}\right] \mathrm{RTX}$ binding and ${ }^{45} \mathrm{Ca}$ uptake in intact DRG neurons (Acs et al., 1996). In the present study, we have extended the evidence by showing that a biological response, desensitization in response to RTX, quanti- 


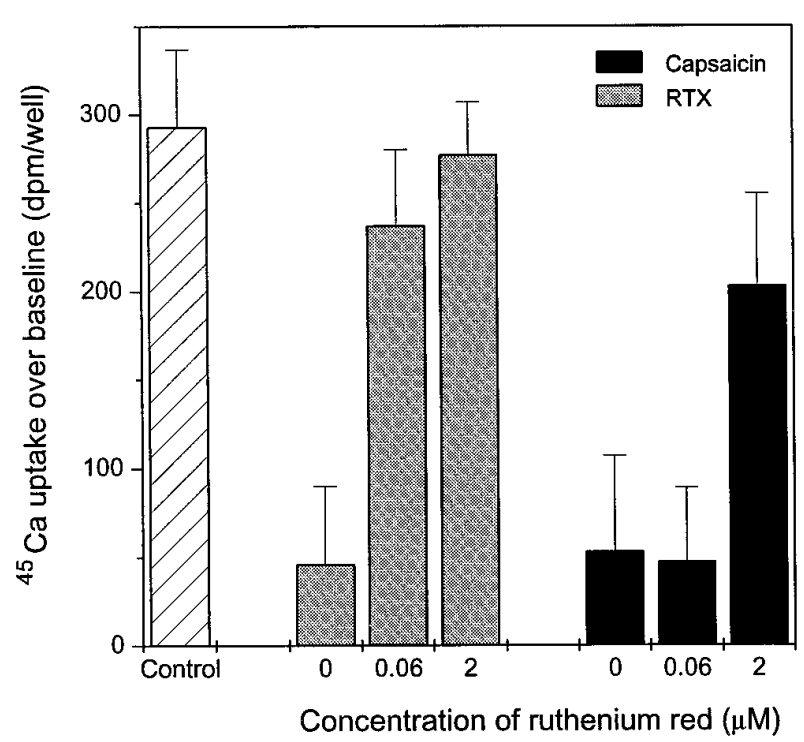

Figure 5. Differential inhibition by ruthenium red of capsaicin and RTXinduced desensitization of rat DRG neurons. Cells were incubated with either $250 \mathrm{pM}$ RTX or $1 \mu \mathrm{M}$ capsaicin for $6 \mathrm{hr}$ in the presence of $60 \mathrm{nM}$ or $2 \mu \mathrm{M}$ ruthenium red, washed three times with serum-free DMEM containing $0.25 \mathrm{mg} / \mathrm{ml} \mathrm{BSA}$ to remove the pretreatment compounds, and then challenged with $3 \mu \mathrm{M}$ capsaicin to induce ${ }^{45} \mathrm{Ca}$ uptake. The return of the ${ }^{45} \mathrm{Ca}$ uptake response in the presence of ruthenium red represents the inhibition of desensitization. Points represent mean values from sets of eight determinations in a single experiment; error bars indicate SEM. Two additional experiments yielded similar results.

tatively agrees with the pharmacology for the R-type receptor. We further show that ruthenium red, a noncompetitive vanilloid antagonist, shows markedly different affinity for blocking responses through the $\mathrm{R}$ - and C-type receptors.

A critical issue was whether the desensitization induced by RTX could simply have been a consequence of a low level of ${ }^{45} \mathrm{Ca}$ uptake induced by RTX occupying a small fraction of the C-type receptors. Three findings argue against this explanation. First, ruthenium red was much more potent for blocking the RTXinduced desensitization compared with ${ }^{45} \mathrm{Ca}$ uptake. Second, the RTX-induced desensitization showed no dependence on external $\mathrm{Ca}^{2+}$, in contrast to the desensitization by capsaicin. Finally, desensitization in response to capsaicin was observed only with an $\mathrm{ED}_{50}$ corresponding to that for induction of ${ }^{45} \mathrm{Ca}$ uptake, not at a concentration an order of magnitude lower.

Elegant previous studies have established that capsaicininduced desensitization is largely dependent on external $\mathrm{Ca}^{2+}$ (Santicioli et al., 1987; Cholewinski et al., 1993; Docherty et al., 1996). Our results with capsaicin are consistent with these observations and provide further support for distinct mechanisms of desensitization mediated by the $\mathrm{R}$ - and C-type vanilloid receptors. Obviously, the ability to separate responses through these two pathways in DRG neurons will depend on ligands of appropriate selectivity and on their use at appropriate concentrations. At higher concentrations, RTX will also act on the C-type receptors and capsaicin on the R-type. An alternative approach for analysis would be to find systems in which only one receptor subtype is expressed. Elsewhere, we will describe characterization of vanilloid responses in a series of non-neuronal cell lines. In these cells, we observe only C-type receptors and not R-type receptors, and the $\mathrm{C}$-type receptors display characteristics quantitatively similar to those described here (T. Biro, M. Maurer, S.
Modarres, N. E. Lewin, C. Brodie, G. Acs, P. Acs, R. Paus, and P. M. Blumberg, unpublished observations).

Our findings help structure and interpret various observations by multiple groups in the vanilloid field. Szallasi and colleagues (1993) (Goso et al., 1993) have reported previously that specific RTX binding in some preparations, e.g., airways and colon, is of low affinity ( $K_{\mathrm{d}}$ values for RTX are $250 \mathrm{pm}$ and $3 \mathrm{~nm}$, respectively) and lacks cooperativity; these characteristics might fit with these measurements reflecting interaction at the lower affinity, ${ }^{45} \mathrm{Ca}$ uptake-coupled receptor site. Interpretation had been clouded somewhat because of the difficulties in accurately defining this low-affinity binding and the known variability in the cooperativity depending on the conditions of membrane preparation (Szallasi and Blumberg, 1993). Like us, Walpole et al. (1996) found differences between the structure-activity relations for ${ }^{45} \mathrm{Ca}$ uptake and RTX binding. In their case, however, binding was performed on membrane preparations, and because the general trend was similar for both assays, they concluded that "the potencies in the ${ }^{45} \mathrm{Ca}$ uptake assay are generally about 10 -fold lower than binding potencies, presumably due to other processes, e.g., uptake into mitochondria being necessary for detection in this assay." In fact, the differences in structure-activity relations are impressive. If one compares the relative potency for binding versus ${ }^{45} \mathrm{Ca}$ uptake, the ratio $\left(K_{\mathrm{i}} / \mathrm{ED}_{50}\right)$ is 0.04 for RTX compared with 15 for capsaicin; RTX thus permits a 375 -fold better selectivity than does capsaicin for the high-affinity RTX binding site compared with the vanilloid receptor mediating ${ }^{45} \mathrm{Ca}$ uptake.

In biological systems, abundant evidence supports distinct structure-activity relations for different biological responses for vanilloids (Holzer, 1991). Such differences are evident not only in comparisons between vanilloids of the RTX and capsaicin classes, but also within each class. Thus, the vanilloid analog olvanil differentially induces desensitization compared with capsaicin (Dickenson et al., 1990; Dray et al., 1990). The dissection of patterns of biological response can be explained most readily by receptor subtypes, although it is also clear that differences in pharmacokinetics can complicate interpretation (Maggi et al., 1990).

Cellular studies of others likewise argue for vanilloid receptor heterogeneity. Liu and Simon (1994), for example, characterized currents induced in single sensory neurons in response to capsaicin and RTX. At least one subset of currents was inducible by capsaicin but not RTX (at the concentration examined), and furthermore, significant differences were found in the desensitization patterns of the different vanilloid-sensitive currents (Liu and Simon, 1996).

The findings reported here have important implications. First, the evidence that vanilloids induce the activation of a nonvoltagedependent, relatively nonselective cation channel in intact cells (Wood et al., 1988; Winter et al., 1990) and in single-channel patch-clamp preparations (Oh et al., 1996) has strongly supported the argument that the vanilloid receptor either is, or is closely associated with, this ion channel. Our findings suggest that a subset of vanilloid receptors, namely those corresponding to the RTX selective subclass, have a different mechanism. Although further studies will be required to define the mechanism for the R-type vanilloid receptor, the potent inhibition of desensitization by ruthenium red argues for the involvement of calcium, consistent with activation of, e.g., the phosphoinositide pathway. In fact, the stimulation of the phosphoinositide pathway in DRG neurons after vanilloid treatment has already been described (Harvey et al., 1995). 
Elegant studies by Walpole and coworkers (1996) have helped define the structural constraints for activity of vanilloids of the capsaicin class and, to a lesser degree, those of the RTX class. Because these analyses have used ${ }^{45} \mathrm{Ca}$ uptake as the measure of activity, it is clear that separate evaluation of structure-activity relations at the R-type vanilloid receptor will be required. Because this latter receptor is coupled to desensitization without ${ }^{45} \mathrm{Ca}$ uptake, derivatives optimized for selectivity to this site may be of particular potential therapeutic interest. Conversely, vanilloid antagonists selective for the ${ }^{45} \mathrm{Ca}$ uptake site should permit enhanced selectivity when used in combination with a vanilloid agonist selective for the R-type receptor. Indeed, on the basis of our limited knowledge of structure-activity relations for the RTX-selective vanilloid receptor, we should be able to enhance the selectivity of RTX by a factor of 10 by coapplication with capsazepine.

\section{REFERENCES}

Acs G, Palkovits M, Blumberg PM (1994a) $\left[{ }^{3} \mathrm{H}\right]$ resiniferatoxin binding by the human vanilloid (capsaicin) receptor. Mol Brain Res 23:185-190.

Acs G, Palkovits M, Blumberg PM (1994b) Comparison of $\left[{ }^{3} \mathrm{H}\right]$ resiniferatoxin binding by the vanilloid (capsaicin) receptor in dorsal root ganglia, spinal cord, dorsal vagal complex, sciatic and vagal nerve and urinary bladder of the rat. Life Sci 55:1017-1026.

Acs G, Palkovits M, Blumberg PM (1995) Trifluoperazine modulates $\left[{ }^{3} \mathrm{H}\right]$ resiniferatoxin binding by human and rat vanilloid (capsaicin) receptors and affects ${ }^{45} \mathrm{Ca}$ uptake by adult rat dorsal root ganglion neurones. J Pharmacol Exp Ther 274:1090-1098.

Acs G, Lee J, Marquez VE, Blumberg PM (1996) Distinct structure-activity relations for stimulation of ${ }^{45} \mathrm{Ca}$ uptake and for high affinity binding in cultured adult rat dorsal root ganglion neurones and dorsal root ganglion membranes. Mol Brain Res 35:173-182.

Amann R, Maggi CA (1991) Ruthenium red as a capsaicin antagonist. Life Sci 49:849-856.

Bevan SJ, Hothi S, Hughes IF, Rang HP, Shah K, Walpole CSJ, Yeats JC (1992) Capsazepine: a competitive antagonist of the sensory neurone excitant capsaicin. Br J Pharmacol 107:544-552.

Blumberg PM, Szallasi A, Acs G (1993) Resiniferatoxin, an ultrapotent capsaicin analog. In: Capsaicin in the study of pain (Wood JN, ed), pp 45-62. London: Academic.

Buck SH, Burks TF (1986) The neuropharmacology of capsaicin: review of some recent observations. Pharmacol Rev 38:179-226.

Cholewinski A, Burgess GM, Bevan S (1993) The role of calcium in capsaicin-induced desensitization in rat cultured dorsal root ganglion neurons. Neuroscience 55:1015-1023.

Davis ME, Akera T, Brody TM, Watson L (1977) Opiate receptor: cooperativity of binding observed in brain slices. Proc Natl Acad Sci USA 74:5764-5766.

Dickenson A, Hughes C, Rueff A, Dray A (1990) A spinal mechanism of action is involved in the antinociception produced by the capsaicin analogue NE 19550 (olvanil). Pain 43:353-362.

Docherty RJ, Yeats JC, Bevan S, Boddeke HWGM (1996) Inhibition of calcineurin inhibits the desensitization of capsaicin-evoked currents in cultured dorsal root ganglion neurons from adult rats. Pflügers Arch 431:828-837.

Dray A, Bettaney J, Rueff A, Walpole CSJ, Wrigglesworth R (1990) NE-19550 and NE-21610, antinociceptive capsaicin analogues: studies on nociceptive fibres of the neonatal tail in vitro. Eur J Pharmacol 181:289-293.

Endrenyi L, Fajszi C, Kwong FH (1975) Evaluation of Hill slopes and
Hill coefficients when the saturation binding or velocity is not known. Eur J Biochem 51:317-328.

Goso C, Evangelista S, Tramontana M, Manzini S, Blumberg PM, Szallasi A (1993) Topical capsaicin administration protects against trinitrobenzene sulfuric acid (TNB)-induced colitis in the rat: characterization of the vanilloid (capsaicin) receptor involved. Eur J Pharmacol 249:185-190.

Harvey JS, Davis C, James IF, Burgess GM (1995) Activation of protein kinase $C$ by the capsaicin analogue resiniferatoxin in sensory neurones. J Neurochem 65:1309-1317.

Hergenhahn M, Adolph W, Hecker E (1975) Resiniferatoxin and other esters of novel polyfunctional diterpenes from Euphorbia resinifera and unispina. Tetrahedron Lett 19:1595-1598.

Holzer P (1991) Capsaicin: cellular targets, mechanisms of action, and selectivity for thin sensory neurons. Pharmacol Rev 43:143-200.

Jancso N (1968) Desensitization with capsaicin and related acylamides as a tool for studying the function of pain receptors. In: Pharmacology of pain, Vol 9 (Linn RKS, ed), pp 33-55. Oxford, UK: Pergamon.

Liu L, Simon SA (1994) A rapid capsaicin-activated current in rat trigeminal ganglion neurons. Proc Natl Acad Sci USA 91:738-741.

Liu L, Simon SA (1996) Capsaicin-induced currents with distinct desensitization and $\mathrm{Ca}^{2+}$ dependence in rat trigeminal ganglion cells. J Neurophysiol 75:1503-1514.

Maggi CA, Patacchini R, Santicioli P, Giuliani S, Geppetti P, Meli A (1988) Protective action of ruthenium red toward capsaicin desensitization of sensory fibers. Neurosci Lett 88:201-205.

Maggi CA, Patacchini R, Tramontana M, Amann R, Giuliani S, Santicioli $P$ (1990) Similarities and differences in the action of resiniferatoxin and capsaicin on central and peripheral endings of primary sensory neurons. Neuroscience 37:531-539.

Oh U, Hwang SW, Kim D (1996) Capsaicin activates a nonselective cation channel in cultured neonatal rat dorsal root ganglion neurons. J Neurosci 16:1659-1667.

Santicioli P, Patacchini R, Maggi CA, Meli A (1987) Exposure to calcium-free medium protects sensory fibers by capsaicin desensitization. Neurosci Lett 80:167-172.

Szallasi A, Blumberg PM (1989) Resiniferatoxin, a phorbol-related diterpene, acts as an ultrapotent analog of capsaicin, the irritant constituent in red pepper. Neuroscience 30:515-520.

Szallasi A, Blumberg PM (1993) [ $\left.{ }^{3} \mathrm{H}\right]$ resiniferatoxin binding by the vanilloid receptor: species-related differences, effects of temperature and sulfhydryl reagents. Naunyn Schmiedebergs Arch Pharmacol 347:84-91.

Szallasi A, Lewin NA, Blumberg PM (1992) Identification of alpha-1acid glycoprotein (orosomucoid) as a major vanilloid binding protein in serum. J Pharmacol Exp Ther 262:883-888.

Szallasi A, Goso C, Blumberg PM, Manzini S (1993) Competitive inhibition by capsazepine of $\left[{ }^{3} \mathrm{H}\right]$ resiniferatoxin binding to central (spinal cord and dorsal root ganglia) and peripheral (urinary bladder and airways) vanilloid (capsaicin) receptors in the rat. J Pharmacol Exp Ther 267:728-733.

Szolcsanyi J, Szallasi A, Szallasi Z, Joo F, Blumberg PM (1990) Resiniferatoxin: an ultrapotent selective modulator of capsaicin-sensitive primary afferent neurons. J Pharmacol Exp Ther 255:923-928.

Walpole CSJ, Bevan S, Bloomfield G, Breckenridge R, James IF, Ritchie T, Szallasi A, Winter J, Wrigglesworth R (1996) Similarities and differences in the structure-activity relationships of capsaicin and resiniferatoxin analogues. J Med Chem 39:2939-2952.

Winter J, Dray A, Wood JN, Yeats JC, Bevan S (1990) Cellular mechanism of action of resiniferatoxin: a potent sensory neuron excitotoxin. Brain Res 520:131-140.

Wood JN, Winter J, James IF, Rang HP, Yeats J, Bevan S (1988) Capsaicin-induced ion fluxes in dorsal root ganglion cells in culture. J Neurosci 8:3208-3220. 